TITLE:

Inside or Outside the Pits : Variable Mobility in Conspecific Sea Urchin, Anthocidaris crassispina (A. Agassiz)

AUTHOR(S):

Yusa, Yoichi; Yamamoto, Tomoko

CITATION:

Yusa, Yoichi ... [et al]. Inside or Outside the Pits : Variable Mobility in Conspecific Sea Urchin, Anthocidaris crassispina (A. Agassiz). PUBLICATIONS OF THE SETO MARINE BIOLOGICAL LABORATORY 1994, 36(4): 255-266

ISSUE DATE:

1994-11-15

URL:

http://hdl.handle.net/2433/176235

RIGHT: 


\title{
Inside or Outside the Pits: Variable Mobility in Conspecific Sea Urchin, Anthocidaris crassispina (A. Agassiz)
}

\author{
YOICHI YUSA \\ Seto Marine Biological Laboratory, Faculty of Science, Kyoto University, \\ Shirahama, Wakayama 649-22, Japan \\ and \\ Томоко Yамамото \\ Department of Zoology, Faculty of Science, Kyoto University, \\ Sakyo-ku, Kyoto 606-01, Japan
}

With Text-figures $1-10$ and Table 1

\begin{abstract}
The sea urchin Anthocidaris crassispina (A. Agassiz) lives either in small pits or outside the pits on rock surfaces. Difference in movement between individuals living inside and outside the pits was investigated. Sea urchins living inside the pits never moved out of their pits either in summer or winter, or during the day or night, while urchins living outside the pits moved in both seasons, especially during the night. Among urchins living outside the pits, individuals occupying relatively sheltered microhabitats (hollows or edges; see Fig. 1) exhibited less movement than individuals occupying open flats. On transplantation to an open area without pits, some individuals previously occupying the pits showed slight movement. On the other hand, most of the individuals previously outside the pits, when transplanted into an area with many vacant pits, occupied them and showed reduced movement, although neither transplanted groups of individuals adjusted their movement perfectly to their new microhabitats during the observation period. These results suggest that the movement of the sea urchins is, to some extent, flexible and dependent on microhabitats and that they preferred sheltered microhabitats. A morphological and physiological investigation showed that sea urchins inside the pits had similar gut weight (with the content), shorter lateral spines and heavier gonads than sea urchins outside the pits of similar test diameter. The adaptive significance of pit-dwelling in $A$. crassispina is discussed.
\end{abstract}

Key words: Anthocidaris crassispina, movement, pit-dwelling, sea urchin

\section{Introduction}

Sea urchins occupy a variety of habitats on rocky shores, and even the same species may be found in different habitats. For instance, Strongylocentrotus franciscanus and $S$. droebachiensis live either in kelp beds or adjacent barren areas (Mattison et al., 1977; Bernstein et al., 1981, 1983). Likewise, Paracentrotus lividus (see Nichol, 1967, p. 651) and Strongylocentrotus purpuratus (see Ebert, 1968; Ricketts \& Calvin, 1968, pp. 202-204) live either in small pits or outside the pits on rock surfaces. Conspecific sea urchins occupying different habitats often differ in physiological and morphological traits (Ebert, 1968; Marcus, 1983), and sometimes in certain behavioural traits. Urchins such as Strongylocentrotus droebachiensis and $S$. franciscanus in kelp forests are known to be less aggregating (Bernstein el al., 1981; Mann, 1985), hide

Publ. Seto Mar. Biol. Lab., 36(4), 255-266, 1994.

(Article 19) 
more in the presence of crabs (Bernstein et al., 1983), feed on drifted pieces of algae rather than on living algae (Mann, 1985) and move in shorter distance per unit time (Mattison et al., 1977) compared with conspecific sea urchins at the edges of kelp forests or in barren areas. Parker \& Shulman (1986) also reported that individuals of Lytechinus variegatus in short, sparse seagrass exhibited an alarm response to the extracts of conspecifics more often than individuals in long, dense seagrass. Except for these behavioural differences in relation to vegetation, little information has been available on the behavioural difference of conspecific sea urchins living in different habitats (but see Parker \& Shulman, 1986). So far no studies have been done regarding the difference in behaviour of urchins living inside or outside the pits, and little is known about their behavioural plasticity in relation to habitat change.

Anthocidaris crassispina (A. Agassiz) is one of the commonest sea urchins along the coasts of Japan, ranging from sublittoral to intertidal zone (Yamanishi \& Tanaka, 1971). This species is abundant in the intertidal rock pools near the Seto Marine Biological Laboratory $\left(33^{\circ} 41^{\prime} \mathrm{N}, 135^{\circ} 20^{\prime} \mathrm{E}\right)$. Individuals often occupy small pits, probably excavated by another species of sea urchin (Echinostrephus aciculatus A. Agassiz) and are also found colonising open rock surfaces. Yamanishi \& Tanaka. (1971) reported that $A$. crassispina inside the pits never moved out of the pits, but they did not mention anything about conspecific urchins outside the pits.

In this study, we examined the difference in movement between $A$. crassispina living inside and outside the pits. A transplanting experiment was conducted to determine the effect of microhabitats on their mobility. Morphological and physiological differences are also reported, and the adaptive significance of pit-dwelling is discussed.

\title{
Materials and Methods
}

\begin{abstract}
Movement of individuals
The movement of sea urchins living inside or outside the pits was investigated in two study areas on an intertidal rocky shore near the laboratory. One area $\left(0.4 \mathrm{~m}^{2}\right)$ covered a small tide pool in which all sea urchins were living inside the pits, and the other area $\left(10 \mathrm{~m}^{2}\right)$ was a part of a larger tide pool and all urchins in the area were living outside the pits (Fig. 1).

Observed sea urchins in both areas were tagged by putting pieces of coloured fine vinyl tubes on some of their spines (Yamanishi \& Tanaka, 1971). The locations of individuals were recorded on maps every 2-4 days during daytime low tide in the summer (from July to August) of 1991 and in the winter (from February to March) of 1992. The tagged individuals were also investigated every 4 hours for 2 days in February 1992. In the winter observation, types of microhabitats outside the pits (hollow, edge or open flat; see Fig. 1) were also recorded. In each of four observed groups (inside or outside the pits in summer and in winter), at least 20 individuals were initially tagged, although many of them lost their tags during the observation periods. On completion of the winter obscrvation, all individuals outside the pits that retained tags were collected for measuring their test diameter.
\end{abstract}

\section{Transplanting experiment}

A transplanting experiment was conducted in other two areas in September 1991. One area $\left(5 \mathrm{~m}^{2}\right)$ covered a relatively small tide pool in which all sea urchins were living inside the pits, and the other $\left(2.5 \mathrm{~m}^{2}\right)$ was a part of a larger tide pool and all sea urchins in the area were living outside the pits. There were no vacant pits in the former area before we experimentally dislodged sea urchins. On 11 th September, 15 individuals inside the pits were taken from the former area, tagged, measured their test diameter and then transplanted into the latter area. These individuals could be taken out of the pits without any major damages. Likewise, 15 individuals outside the pits from the 
a) Pitted area

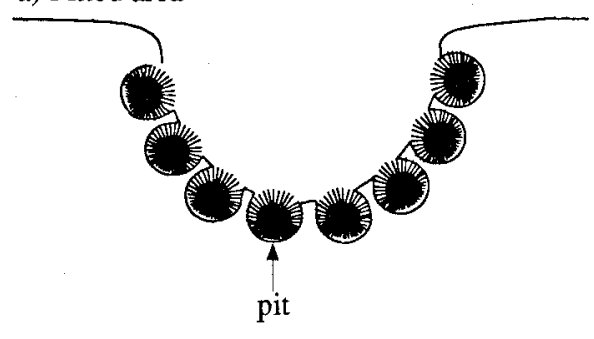

b) Non-pitted area

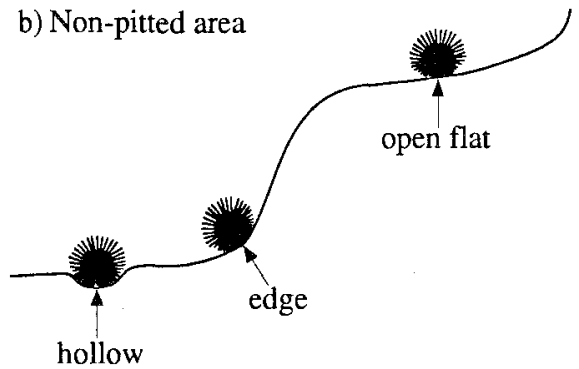

Fig. 1. Study areas with different microhabitats: (a) pitted area; (b) non-pitted area. A pit refers to an excavation which covers at least half of the urchin's test, and a hollow covers less than half of the test.

latter area were released into the former area, from which many other individuals were further taken away to make more vacant pits. Test diameter of individuals in these two transplanted groups was set similar (mean $\pm \mathrm{SE}=36.9 \pm 1.0 \mathrm{~mm}$ and $37.1 \pm 0.8 \mathrm{~mm}$, respectively; $\mathrm{P}=0.6$, Mann-Whitney U-test). The locations and types of microhabitats of tagged sea urchins in both areas were recorded on maps at intervals of 1-4 days. Since many tags were dislodged from urchins transplanted into the area without pits, five individuals (test diameter, $36.6 \pm 1.4 \mathrm{~mm}$ ) were added to the transplanted group during the experimental period. In the same two areas, movement of other 15 individuals inside the pits and 10 outside the pits were also monitored. All these untransplanted individuals were tagged in situ and were not detached from the substrata.

\section{Morphological and physiological differences}

In September 1992, late in the reproductive season near the laboratory (Kobayashi, 1971, 1985), individuals of similar test diameter were collected from the two areas used for the investigation of urchins' movement. Collection was made four times at 5 or 6-day intervals (9th, 15th, 20th and 26th), and three to seven individuals were collected from each area at each, sampling (as a whole 19 individuals inside the pits and 20 outside the pits were collected). They were fixed in $10 \%$ sea water formalin until further examination.

After excess fluid was removed, test diameter, height and wet weight were measured for each fixed specimen. The lengths of three longest spines from the upper $1 / 3$ part and from the middle $1 / 3$ part of the test were also measured. The gut with the content and gonads of the individuals were dissected out, and weighed after drying in an oven at $60^{\circ} \mathrm{C}$ for 24 hours.

\section{Statistical analysis}

All the statistical tests conducted in this study are non-parametric two-tailed tests (Sokal \& Rohlf, 1981).

\section{Results}

\section{Movement of individuals}

Sea urchins inside the pits showed no movement either in summer (Fig. 2a) or in winter (Fig. 2b). Sea urchins outside the pits, on the other hand, moved in both seasons (Fig. 2a \& b). The distance moved by individuals living in different microhabitats was significantly different in both seasons (Fig. 3), but difference between seasons was not significant for sea urchins in both microbabitats $(P=1$ for urchins inside the pits; $\mathrm{P}=0.8$ for urchins outside; Mann-Whitney U-test).

Individuals inside the pits never came out of their pits irrespective of the time of the day (Fig. 4). In contrast, individuals outside the pits showed some movement 
(a) Summer

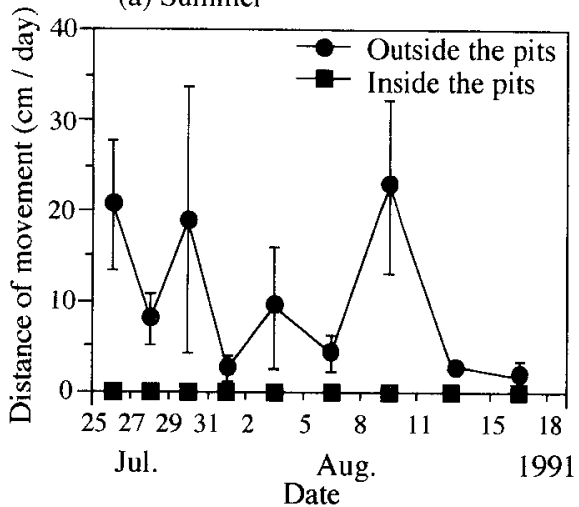

(b) Winter

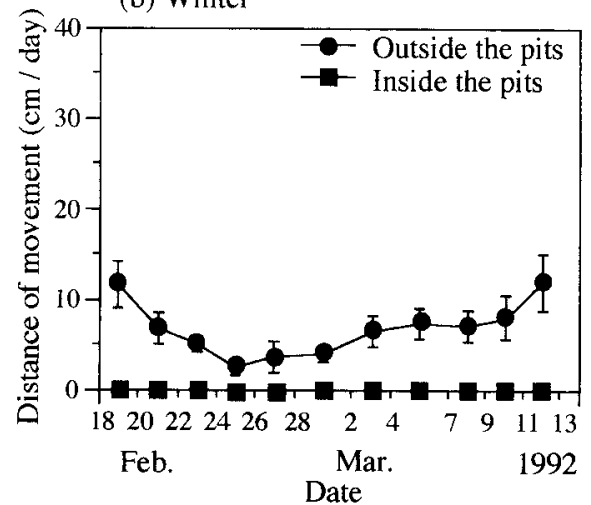

Fig. 2. Changes in the mean distance moved ( $\mathrm{cm} /$ day) by sea urchins inside (squares) or outside the pits (circles). (a) Summer; (b) winter. Vertical bars show SE.

(a) Inside the pits - summer

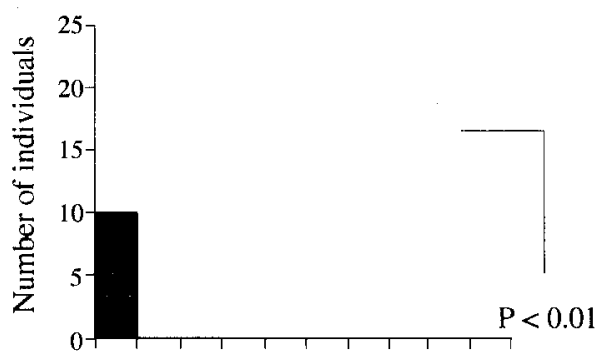

(c) Outside the pits - summer

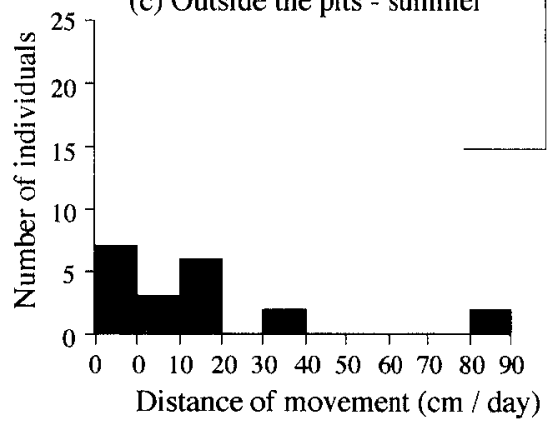

(b) Inside the pits - winter

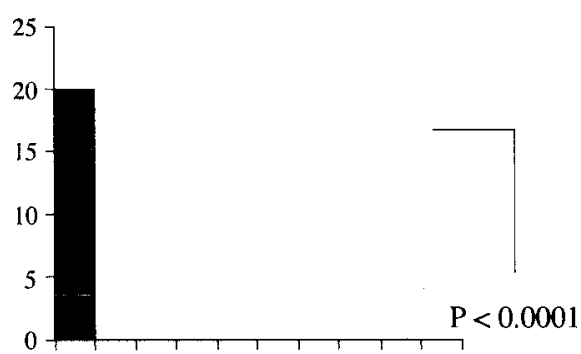

(d) Outside the pits - winter

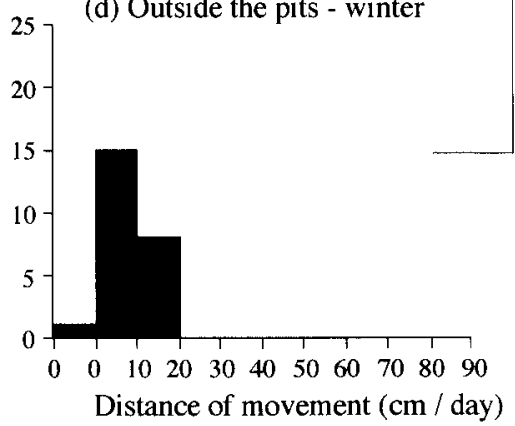

Fig. 3. Number of individuals showing variable mobility ( $\mathrm{cm} /$ day) for (a) urchins inside the pits in summer, (b) urchins inside the pits in winter, (c) urchins outside the pits in summer, and (d) urchins outside the pits in winter. Bars at $0-0$ interval indicate number of individuals which did not move. Only data taken at 2-day intervals were averaged for each individual to make comparisons meaningful. Individuals that had at least two such data are shown. Probability levels are according to Mann-Whitney U-test. 


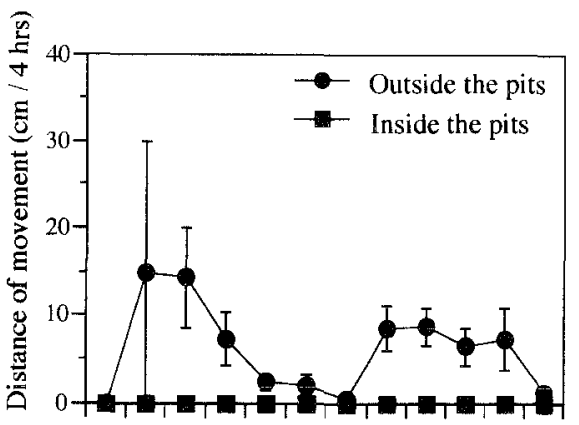

Tide stage

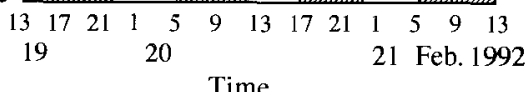

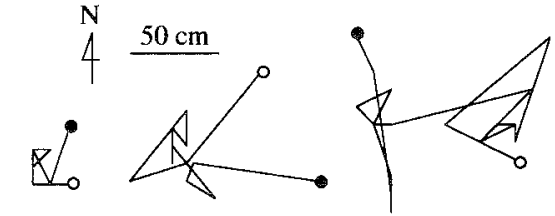

$22.8 \mathrm{~mm} \quad 25.7 \mathrm{~mm}$
$21.8 \mathrm{~mm}$
Fig. 4. Diel changes in the mean distance moved (cm/4 hours) by individuals inside (squares) or outside the pits (circles). Vertical bars show SE. Hatched areas in the lower belt indicate the times when the pools were submersed, open areas when emersed.

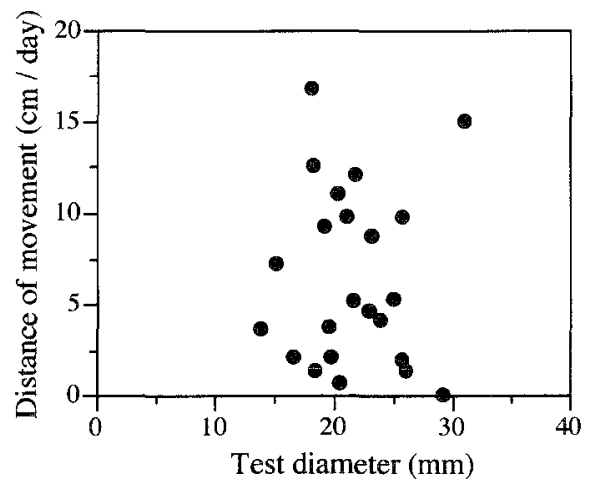

Fig. 6. Distance moved (cm/day) by individuals outside the pits as a function of test diameter, observed in the winter of 1992. $\mathrm{N}=23, \tau=-0.08, \mathrm{P}=0.6$; Kendall's rank correlation. Datum for one individual is lacking compared with Figs. $3 d$ \& 7 , because the individual was not found when test diameter was measured.
Fig. 5. Examples of changes in location by three individuals outside the pits, recorded in the winter of 1992. Open circles indicate the starting points (recorded on 18th February), and closed circles the final points (13th March). Test diameter of each individual is shown under locus. Relationships in location among individuals are not exact.

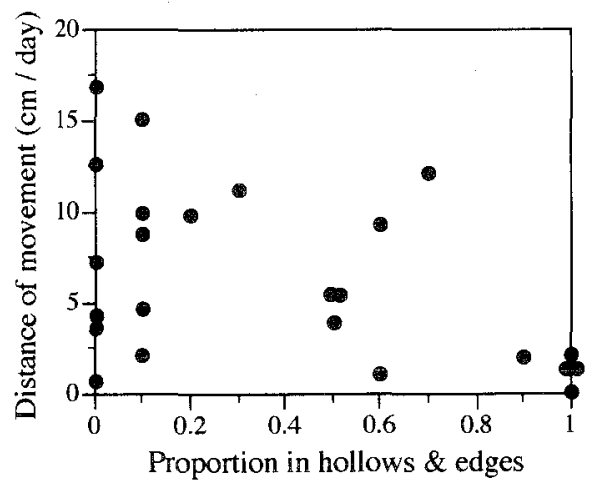

Fig. 7. Distance moved ( $\mathrm{cm} /$ day) by individuals outside the pits as a function of the proportion in which they were found in relatively sheltered microhabitats (hollows and edges), observed in the winter of 1992. There are 2 points at (1, 1.25). $\mathrm{N}=24, \quad \tau=-0.31, \quad \mathrm{P}<0.05$; Kendall's rank correlation. 
at any time, except between $1300-1700 \mathrm{~h}$. The mean distance of movement by each individual during the night $(1700-0500 \mathrm{~h})$ was greater than that during the day $(0500-1700$ h; $\mathrm{P}<0.001$; Wilcoxon's signed ranks test). On the other hand, the mean distance of movement was not different either when the observed pool was emersed or submersed $(\mathrm{P}=0.8)$.

Sea urchins outside the pits moved undirectionally, without any specific resting sites (Fig. 5). The distance of movement was not significantly correlated with test diameter (Fig. 6), indicating that body size was not responsible for the variation in the distance moved among individuals outside the pits. However, individuals that tended to occupy relatively sheltered microhabitats (hollows or edges) moved in shorter distance than individuals that tended to occupy open flats (Fig. 7).

\section{Transplanting experiment}

As in summer and in winter (Fig. 2), untransplanted individuals inside the pits did not move at all in this experiment conducted in autumn (Fig. 8a). Also as in summer and in winter, untransplanted individuals outside the pits showed some movement (Fig. 8d). In both transplanted groups (from a pitted area into an open area without pits and vice versa; Fig. $8 \mathrm{~b} \& \mathrm{c}$ ), individuals moved much just after transplanting, but then they reduced their mobility. Since such change in distance moved was not observed in the untransplanted groups, the greater mobility of the transplanted groups just after transplanting may be due to disturbance. Accordingly, we excluded the data for the first and second points in Fig. 8b \& $c$ from comparisons in the distance moved between experimental groups (Fig. 9).

In Fig. 9, mean distance moved per day by each individual was pooled for each experimental group. Although most individuals did not show any movement, some individuals previously inside the pits started to move when transplanted into an open area without pits (Fig. 9b). Thus, there was a significant difference in the distance moved between untransplanted individuals inside the pits and the transplanted ones (comparison between Fig. $9 \mathrm{a} \&$ b). However, the movement of transplanted individuals was significantly less than that of untransplanted ones outside the pits (Fig. 9b \& d). A similar but opposite tendency was seen when individuals previously outside the pits were transplanted into an area with vacant pits (Fig. 9c). They significantly reduced their movement compared with untransplanted individuals outside the pits (comparison between Fig. 9c \& d), but their distance of movement was greater than that of untransplanted ones inside the pits (Fig. 9c \& a).

Unlike sea urchins outside the pits in the winter observation (Fig. 7), there was no correlation between the tendency to occupy hollows or edges and the distance moved among sea urchins transplanted from the pits into the open area (Fig. 10a), although this lack of correlation may be due to small sample size $(\mathrm{N}=9)$. Among sea urchins transplanted from the open area into the pitted area, there was a negative correlation between tendency to occupy pits and the distance moved per day (Fig. 10b). In the latter transplanted group, seven individuals with the least movement were found exclusively inside the pits, three individuals with moderate movement were inside the pits in at least half of the observations. The one with the greatest 


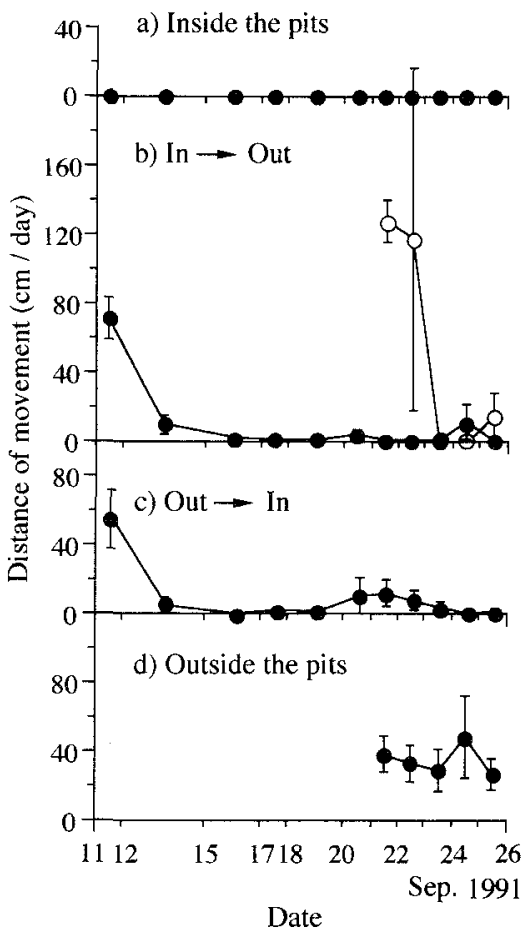

Fig. 8. Changes in the mean distance moved (cm/day) by (a) untransplanted urchins inside the pits, (b) urchins transplanted from pits into an open area without pits, (c) urchins transplanted from an open area into an area with vacant pits, and (d) untransplanted urchins outside the pits. Vertical bars show SE. Open circles in (b) show data for individuals that added later in the observation period.

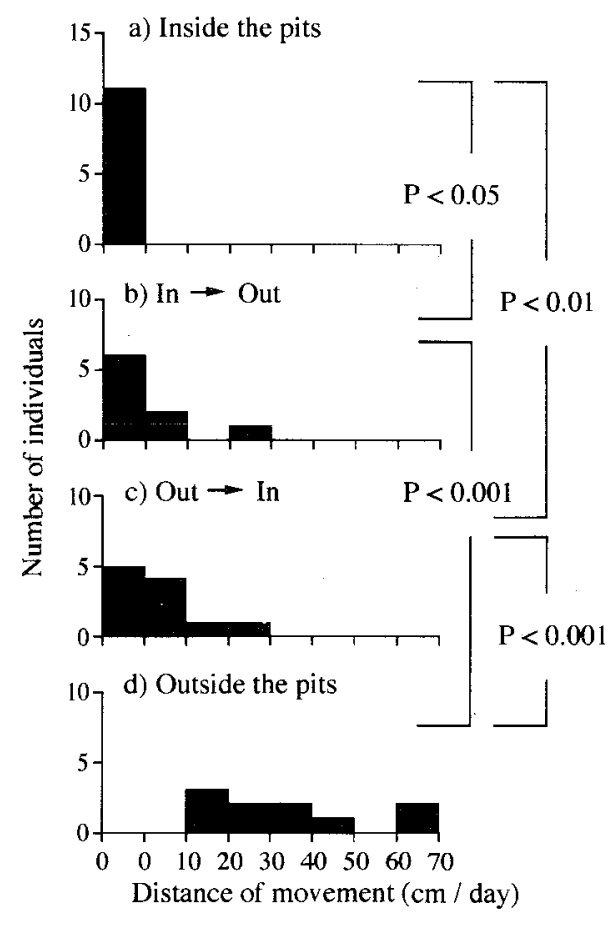

Fig. 9. Number of individuals showing variable mobility ( $\mathrm{cm} / \mathrm{day}$ ), for (a) untransplanted urchins inside the pits, (b) urchins transplanted from pits into an open area without pits, including those added later in the observation period, (c) urchins transplanted from an open area into an area with vacant pits, and (d) untransplanted urchins outside the pits. Bars at $0-0$ interval indicate number of individuals which did not move. Only data taken at daily intervals were averaged for each individual, and urchins that had at least two data arc shown. Probability levels are according to Mann-Whitney U-test.

mobililty was never observed to enter in vacant pits, although there were many vacant pits in the study area.

\section{Morphological and physiological differences}

Among individuals of similar test diameter (D), no significant differences were found in height $(\mathrm{H}), \mathrm{D}^{2} \mathrm{H}$, or wet weight between individuals inside the pits and those outside (Table 1). Neither did the average length of three longest spines from the upper $1 / 3$ part of the test differ between the two microhabitats, but spines from the lateral $1 / 3$ part were significantly shorter in individuals inside the pits than those 

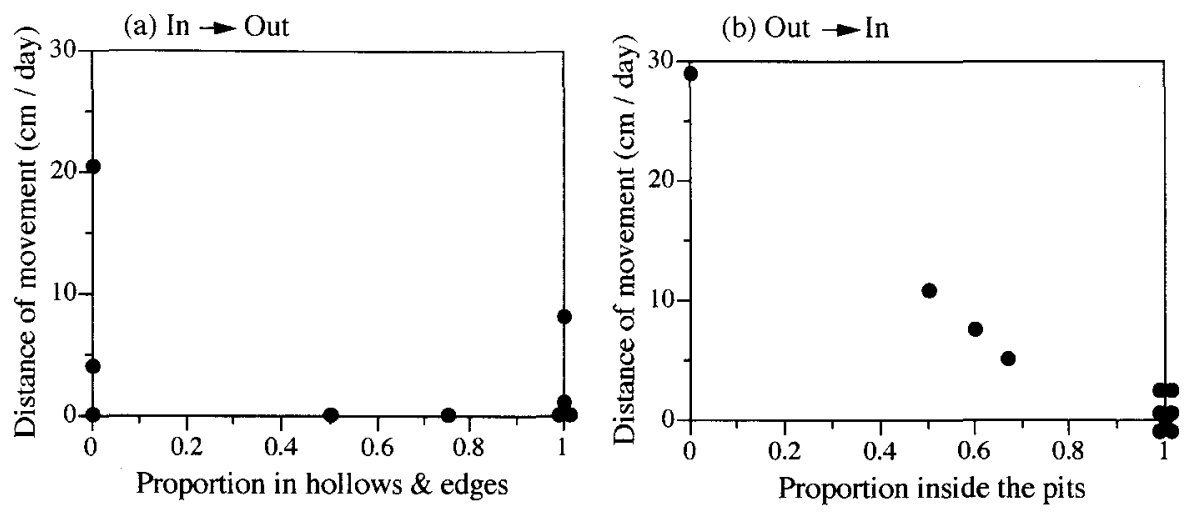

Fig. 10. Distance moved ( $\mathrm{cm} /$ day) by transplanted individuals as a function of the proportion in which they were found in sheltered microhabitats. (a) Urchins transplanted from the pits into an open area without pits; (b) urchins transplanted from an open area into an area with vacant pits. Sheltered microhabitats refer to hollows and edges in (a) and pits in (b). There are 3 points at $(1,0)$ in (a), and 5 points at $(1,0)$ in (b). (a) $\mathrm{N}=9, \tau=-0.29, \mathrm{P}=0.3$; (b) $\mathrm{N}=11, \tau=-0.88, \mathrm{P}<0.001$; Kendall's rank correlation.

Table 1. Morphological and physiological differences between individuals inside and outside the pits (mean $\pm \mathrm{SE}$ ). Probability levels are according to Mann-Whitney U-test.

\begin{tabular}{lccc} 
& Inside the pits & Outside the pits & P \\
\hline $\mathrm{N}$ & 19 & 20 & \\
Test diameter: $\mathrm{D}(\mathrm{mm})$ & $35.1 \pm 1.1$ & $34.6 \pm 1.0$ & 0.7 \\
Test height: $\mathrm{H}(\mathrm{mm})$ & $19.1 \pm 0.7$ & $17.7 \pm 0.5$ & 0.2 \\
$\mathrm{D}^{2} \mathrm{H}\left(\mathrm{cm}^{3}\right)$ & $24.9 \pm 2.4$ & $22.2 \pm 1.8$ & 0.5 \\
Wet weight $(\mathrm{g})$ & $23.2 \pm 1.9$ & $21.3 \pm 1.5$ & 0.6 \\
Upper spines $(\mathrm{mm})$ & $31.3 \pm 0.8$ & $31.8 \pm 1.1$ & 0.7 \\
Lateral spines $(\mathrm{mm})$ & $23.4 \pm 1.1$ & $26.6 \pm 1.3$ & $<0.05$ \\
Gut dry weight $(\mathrm{g})$ & $0.45 \pm 0.05$ & $0.50 \pm 0.05$ & 0.5 \\
Gonad dry weight $(\mathrm{g})$ & $0.32 \pm 0.05$ & $0.09 \pm 0.02$ & $<0.001$
\end{tabular}

outside (Table 1). No difference was found in the dry weight of the gut with its content between the two groups. Although food quality was not investigated in detail, the gut content of individuals in both microhabitats was similar and consisted of silt and algal fragments, suggesting deposit feeding in autumn (but see Yamanishi \& Tanaka, 1971). Individuals inside the pits, however, had much heavier gonads than those outside the pits (Table 1). 


\section{Discussion}

The sea urchin Anthocidaris crassispina showed differential movement in relation to their microhabitats. It is obvious that urchins in sheltered microhabitats showed less movement than those in exposed areas. Firstly, urchins inside the pits did not exhibit movement irrespective of the season or time, while those outside the pits showed some movement both in summer and winter, especially during the night. Secondly, among urchins inhabiting outside the pits, those occupying relatively sheltered microhabitats (hollows or edges) exhibited less movement than those occupying open flats. A similar case was noticed in individuals transplanted from the open area into the pitted area.

Differential movement by conspecific sea urchins depending upon food availability has already been reported. For example, Strongylocentrotus franciscanus tends to move longer distance when food supply is low (Mattison et al., 1977; Russo, 1979). More similar results to ours were reported by Bernstein et al. (1981) and Mann (1985). In $S$. droebachiensis, both authors reported that individuals in kelp forests seem never to emerge from crevices. On the other hand, individuals on coralline flats hide in crevices during the day and forage during the night in summer (but in winter most individuals were out). Mann (1985) recognised a clear difference in feeding behaviour in this species and termed the feeding behaviour of urchins in kelp forests "passive detrivore mode" and that of urchins on coralline flats "browsing mode." He also reported other differences in vegetation and urchin density relevant to this distinction. However, neither this distinction of feeding behaviour nor the relevant differences apply to $A$. crassispina inside or outside the pits. Firstly, our investigation of the gut content showed that $A$. crassispina in both microhabitats fed on detritus in autumn, suggesting a similar "feeding mode". Secondly, unlike in the case of $S$. droebachiensis in which habitats were distinguished based on differential vegetation, both microhabitats of $A$. crassispina lacked visible algae. Thirdly, although Mann (1985) states that the density of immobile urchins (about $0.1 / \mathrm{m}^{2}$ ) was much lower than that of mobile urchins $\left(30-100 / \mathrm{m}^{2}\right)$, our observation in July 1991 showed that the density of immobile urchins inside the pits $\left(205 / \mathrm{m}^{2}\right)$ was higher than the highest density $\left(55 / \mathrm{m}^{2}\right)$ of mobile urchins outside the pits. Considering that factors such as urchin density or the presence of predators are suggested to affect aggregation (Bernstein et al., 1981; Mann, 1985, Hagen \& Mann, 1994), homing behaviour (Carpenter, 1984), diel activity rhythm (Nelson \& Vance, 1979) or alarm response (Parker \& Shulman, 1986), food availability may not be the single factor affecting movement in sea urchins.

The transplanting experiment indicated that the movement of $A$. crassispina is to some extent flexible. However, it is yet to be confirmed whether the movement of sea urchins is dependent solely on microhabitats or not. Since we did not detach untransplanted sea urchins from their microhabitats at the beginning of the experiment unlike transplanted urchins, it is logically impossible to distinguish the effect of handling and that of microhabitat change by this experiment alone (Underwood, 1988). However, the negative correlations between the tendency to occupy relatively 
sheltered microhabitats and distance moved, found in individuals outside the pits and in transplanted individuals into the pitted area, support the effect of microhabitats on sea urchins' mobility. Though the movement of sea urchins appears to be flexible and dependent on microhabitats, such flexibility may be limited, since the transplanted urchins did not adjust their movement immediately and completely to their new habitats. Whether genetic (Marcus, 1983; Tsuchiya \& Nishihira, 1985) or other unchangeable differences exist between sea urchins in different microhabitats is yet to be confirmed.

When transplanted to the pitted area, most sea urchins previously living outside the pits reduced their mobility and occupied vacant pits. Similarly, individuals outside the pits exhibited reduced mobility after occupying hollows or edges. These results suggest that sea urchins, in general, preferred to live in sheltered microhabitats. The fact that no vacant pits were found in the study area before our experiment is consistent with the view that individuals living outside the pits were forced to stay there due to the lack of vacant pits. The preference for sheltered habitats over open ones was also suggested in the case of Echinometra mathaei by Khamala (1971).

Then, what are the possible advantages of living inside the pits in Anthocidaris crassispina, compared with living in open habitats? An answer must be the realisation of higher reproductive success, as indicated by heavier gonads of sea urchins inside the pits than those outside of similar size.

Presumably, the difference in gonad weight was not caused by the difference in food availability, since individuals inside the pits had similar gut weight and gut content as in individuals outside of similar body size. More likely, heavier gonads of urchins inside the pits may have been due to their higher resource allocation to reproduction relative to other activities. Judging from the data presented, there are two possible ways in which they can attain higher allocation to ganads. First, individuals inside the pits can save energy owing to their immobility. Secondly, shorter lateral spines of individuals inside the pits suggests that they can also save resources utilised for spine growth. Although the amount of resources required for the growth of a single spine may be negligible, the total amount for regenerating many spines may be fairly large. The effect of spine regeneration is known to be so large as to influence growth rate (Ebert, 1968) and resource allocation pattern (Edwards \& Ebert, 1991) in Strongylocentrotus purpuratus. Moreover, Ebert (1968) suggested that spine regeneration following breakage is less frequent for individuals inside the pits than those outside.

Another possible advantage of pit-dwelling is greater survival. Factors such as wave action (Sharp \& Gray, 1962; Ebert, 1968; Snyder \& Snyder, 1970; Khamala, 1971; Yamanishi \& Tanaka, 1971) and the presence of predators (Moore, 1966; Bernstein et al., 1981, 1983; Parker \& Shulman, 1986; Scheibling \& Hamm, 1991; Hagen \& Mann, 1994, but see also Vadas et al., 1986) have been suggested to be important to the survival in many sea urchin species. Both factors are avoided to the maximum inside the pits. However, A. crassispina in both microhabitats in our study area may survive fairly well, since we noticed no dead urchins during our study. 
A possible disadvantage of pit-dwelling is the limitation of maximum body size. However, this possible disadvantage may be of negligible importance, since in a nearby area there was no difference $(\mathrm{P}=0.9 ;$ Mann-Whitney U-test) in test diameter between individuals inside the pits (mean $\pm \mathrm{SE}=30.6 \pm 1.2 \mathrm{~mm}, \mathrm{~N}=39$ ) and those outside the pits $(30.1 \pm 1.6 \mathrm{~mm}, \mathrm{~N}=37)$.

\section{Acknowledgements}

We thank Keiji Iwasaki and Makoto Yamazaki for informing us of relevant literature. Discussions with Naomasa Kobayashi, Ryohei Yamanishi, Shigeyuki Yamato and the members of the "Argonauts" (Kyoto Marine Biological Seminar) improved our ideas. Eiji Harada, Keiji Iwasaki, Moritaka Nishihira and T. V. Raveendran gave valuable comments on the manuscript.

\section{References}

Bernstein, B. B., Schroeter, S. C. \& Mann, K. H. 1983. Sea urchin (Strongylocentrotus droebachiensis) aggregating behavior investigated by a subtidal multifactorial experiment. Can. J. Fish. Aquat. Sci,, 40: 1975-1986.

Bernstein, B. B., Williams, B. E. \& Mann, K. H. 1981. The role of behavioral responses to predators in modifying urchins' (Strongylocentrotus droebachiensis) destructive grazing and seasonal foraging patterns. Mar. Biol., 63: 39-49.

Garpenter, R. G. 1984. Predator and population density control of homing bchavior in the Caribbean echinoid Diadema antillarum. Mar. Biol., 82: 101-108.

Ebert, T. A. 1968. Growth rates of the sea urchin Strongylocentrolus purpuratus related to food availability and spine abrasion. Ecology, 49(6): 1075-1091.

Edwards, P. B. \& Ebert, T. A. 1991. Plastic responses to limited food availability and spine damage in the sea urchin Strongylocentrotus purpuratus (Stimpson). J. Exp. Mar. Biol. Ecol., 145: 205-220.

Hagen, N. T. \& Mann, K. H. 1994. Experimental analysis of factors influencing the aggregating behaviour of the green sea urchin Strongylocentrotus droebachiensis (Müller). J. Exp. Mar. Biol, Ecol., 176: $107-126$.

Khamala, C. P. M. 1971. Ecology of Echinometra mathaei (Echinoidea: Echinodermata) at Diani Beach, Kenya. Mar. Biol., 11: 167-172.

Kobayashi, N. 1971. Method for experiments on the development of sea urchins. The Nanki Seibitu, 13(2): 38-44. [in Japanese]

- 1985. Bioassays of Water Pollution, Using Aquatic Invertebrates, Scientist Co., Tokyo. 209 pp. [in Japanese]

Mann, K. H. 1985. Invertebrate behaviour and the structure of marine benthic communities. In: R. M. Sibly \& R. H. Smith (eds.), Behavioural Ecology, Blackwell, Oxford. 227-246.

Marcus, N. 1983. Phenotypic variability in echinoderms. In: M. Jangoux \& J. M. Lawrence (eds.), Echinoderm Studies I, A. A. Balkema, Rotterdam. 19-37.

Mattison, J. E., Trent, J. D., Shanks, A. L., Akin, T. B. \& Pearse, J. S. 1977. Movement and feeding activity of red sea urchins (Strongylocentrotus franciscanus) adjacent to a kelp forest. Mar. Biol., 39: 25-30.

Moore, H. B. 1966. Ecology of echinoids. In: R. A. Boolootian (ed.), Physiology of Echinodermata, John Wiley \& Sons, New York. 73-85.

Nelson, B. V. \& Vance, R. R. 1979. Diel foraging patterns of the sea urchin Centrostephanus coronatus as a predator avoidance strategy. Mar. Biol., 51: 251-258.

Nichol, J. A. C. 1967. The Biology of Marine Animals, 2nd ed., Sir lsaac Pitman \& Sons, London. 699 pp.

Parker, D. A. \& Shulman, M. J. 1986. Avoiding predation: alarm responses of Caribbean sea urchins to simulated predation on conspecific and heterospecific sea urchins. Mar. Biol., 93: 201-208.

Ricketts, E. F. \& Calvin, J. 1968. Between Pacific Tides, 4th ed., Stanford University Press, Galifornia. $614 \mathrm{pp}$.

Russo, A. R. 1979. Dispersion and food differences between two populations of the sea urchin Strongylocentrotus franciscanus. J. Biogeogr., 6: 407-414.

Scheibling, R. E. \& Hamm, J. 1991. Interactions between sea urchins (Stronglocentrotus droebachiensis) 
and their predators in field and laboratory experiments. Mar. Biol., 110: 105-116.

Sharp, D. T. \& Gray, I. E. 1962. Studies on factors affecting the local distribution of two sea urchins, Arbacia punctulata and Lytechinus variegatus. Ecology, 43(2): 309-313.

Snyder, N. \& Snyder, H. 1970. Alarm response of Diadema antillarum. Science, 168: 276-278.

Sokal, R. R. \& Rohlf, F. J. 1981. Biometry, 2nd ed., W. H. Freeman and Company, New York. 859 pp.

Tsuchiya, M. \& Nishihira, M. 1985. Agonistic behavior and its effect on the dispersion pattern in two types of the sea urchin, Echinometra mathaei (Blainville). Galaxea, 4: 37-48.

Underwood, A. J. 1988. Design and analysis of field experiments on competitive interactions affecting behaviour of intertidal animals. In: G. Chelazzi \& M. Vannini (eds.), Behavioral Adaptation to Intertidal Life, Plenum, New York. 333-357.

Vadas, R. L., Elner, R. W., Garwood, P. E. \& Babb, I. G. 1986. Experimental evaluation of aggregating behavior in the sea urchin Strongylocentrotus droebachiensis. Mar. Biol., 90: 433-448.

Yamanishi, R. \& Tanaka, A. 1971. Contributions to the biology of littoral sea urchins. I. Measurements of clinging power and observations on stability of sea urchin colonies. Publ. Seto Mar. Biol. Lab., 19(1): $2-15$. 